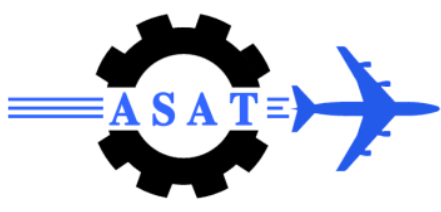

\title{
Numerical Simulation of PV-Hydrogen Electrolyzes System
}

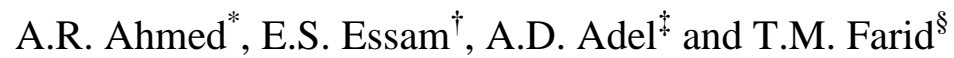

\begin{abstract}
A numerical simulation was developed for a PV-Hydrogen Electrolyzes system. The system is simply consisted of a PV that feeds Hydrogen electrolyzes cell by electric power. The system was successfully installed and experimentally tested. Each system component was numerically modeled and the governing equations were solved as a steady solution for each time step. The simulation was running along the simulation period of time. TRNSYS 15 program was used to establish the simulation. The simulation results are verified with the corresponding measured data for the same system geometry and under the weather conditions of Egypt. It is found that the simulated Hydrogen flow rate approximately agrees with that produced experimentally where the maximum Hydrogen generation is about $43 \mathrm{ml} / \mathrm{min}$. The difference between the measured and predicted $\mathrm{H}_{2}$ flow rate during the day hours is about $4 \%$. The daily overall efficiency of the system is ranged from 2.8 to $4.2 \%$ in both simulated and experimental data. The overall efficiency of the system along the year is approximately between 2.45 to $2.75 \%$ and that is according to the total solar radiation incident and the amount of electric power delivered to the Hydrogen cell with the amount of hydrogen produced as well as the total hydrogen produced annually was 41407931.97 liters. The simulation program is approximately validated and can be used for the predication of the considered system performance.
\end{abstract}

Keywords: Solar PV, Hydrogen, Electrolyzes, Numerical simulation, TRNSYS

\section{Nomenclature}

$\mathrm{A}_{\mathrm{m}} \quad$ the PV module's area $\left(\mathrm{m}^{2}\right)$

$\mathrm{C}$ device specific constant of solar cell material (dimensionless).

E the calorific value of the Hydrogen

F Faraday constant.

$\mathrm{G} \quad$ Total radiation incident on PV array $\left(\mathrm{W} / \mathrm{m}^{2}\right)$

$\mathrm{G}_{\mathrm{r}} \quad$ Incident radiation at reference conditions (i.e. temperature is $25^{\circ} \mathrm{C}$ and solar radiation is $1000 \mathrm{~W} / \mathrm{m}^{2}$ ).

K Boltzmann constant.

$\mathrm{N}_{\mathrm{p}} \quad$ Number of modules in parallel in array.

\footnotetext{
* Engineer, Faculty of Engineering, Mattaria, Helwan University, 11718 Cairo, Egypt, amadoo77@yahoo.com

${ }^{\dagger}$ Assoc. Prof., Solar Energy Dept., National Research Centre, Cairo, Egypt, essamahame@hotmail.com

* Assoc. Prof., Faculty of Engineering, Om El koura University, Saudi Arabia, adel_abdeldayem@hotmail.com

$\S$ Assoc. Prof., Faculty of Engineering, Arab Academy for Science and Technology, Cairo, tantmfarid@hotmail.com
} 
$\mathrm{I}_{\mathrm{o}} \quad$ Reverse saturation current (A).

I $l r \quad$ photocurrent at reference conditions (A).

$\mathrm{N}_{\mathrm{S}} \quad$ Number of modules in series in array.

$\mathrm{N}_{\mathrm{c}} \quad$ Number of individual cells in module.

$\mathrm{R}$ the temperature dependence of the ohmic resistance parameter

$\mathrm{s} \& \mathrm{t}$ the over voltage coefficients.

$\mathrm{T}_{\mathrm{s}} \quad$ Surface temperature of PV module $\left({ }^{\circ} \mathrm{C}\right)$.

$\mathrm{T}_{\mathrm{sr}} \quad$ Surface temperature of PV module $\left({ }^{\circ} \mathrm{C}\right)$ at reference conditions.

$\mathrm{V}_{\text {tr }} \quad$ Thermal voltage at reference conditions.

$\mathrm{V}_{\text {ocr }} \quad$ Open voltage at reference conditions.

$\mathrm{Z}$ the number of electrons.

\section{Greek Symbols}

$\Delta$ Gs change in Gibbs energy.

$\Delta \mathrm{H} \quad$ The enthalpy for splitting water.

$\Delta \mathrm{S} \quad$ The entropy for splitting water.

$\mu_{\mathrm{sc}} \quad$ Temperature coefficient of short-circuit current $[\mathrm{A} / \mathrm{K}]$.

\section{Introduction}

There is a growing awareness that hydrogen is the fuel of the future. A logical source for large-scale hydrogen production is water, which is abundant on earth. While hydrogen can be generated using different technologies, only some of them are environmentally friendly. It is argued that hydrogen generated from water using solar energy, solar-hydrogen, is a leading candidate for a renewable and environmentally safe energy carrier.

Electrolysis appears to be the only method developed which can be used for large-scale hydrogen production in post-fossil fuel era. Production of hydrogen by water electrolysis is a more than 50-year old technology, based on a fundamentally simple process, is very efficient, and does not involve moving parts.

The total theoretical water decomposition potential is $1.480 \mathrm{~V}$ corresponding to hydrogen's enthalpy (since $\Delta \mathrm{H}=\Delta \mathrm{G}+\mathrm{T} \Delta \mathrm{s}$ ). Due to irreversible processes occurring at the anode and cathode, including the electrical resistance of the cell, the actual potentials are always higher, typically between 1.75 and $2.05 \mathrm{~V}$.

Several electrolyzer technologies are being developed, such as:

- Alkaline electrolysis, which employs new materials for membranes and electrodes that allow further improvement in efficiency up to $90 \%$.[1,2].

- Solid polymer electrolytic (SPE) process, which employs a proton conducting ion exchange membrane as electrolyte and as membrane that separates the electrolysis cell. This type of electrolyzers can operate at very high current densities.

An electrolysis plant can operate over a wide range of capacity factors and is convenient for a wide range of operating capacities, which makes this process interesting for coupling with renewable energy sources, particularly with photovoltaic. Photovoltaic generate low voltagedirect current, exactly what is required for the electrolysis process. 
The performance of photovoltaic-electrolyzer systems has been studied extensively both in theory and in practice [3]. Several national programs are currently operating all over the world, such as:

- Solar-Wasserstoff-Bayern pilot plant in Neunburg vorm Wald in Germany [4].

- HYSOLAR project in Saudi Arabia [5].

- Schatz Energy center, Humboldt State University, Arcata, California [6].

- Helsinki University of Technology, Helsinki, Finland [7].

- $\quad$ INT A Energy Laboratory, Huelva, Spain [8].

Kerimov et al. [9] have carried out on the basis of experimental investigations in natural conditions giving one of the possible schemes of mathematical model of solar electrolysis plant for the production of Hydrogen and Oxygen from water under pressure. The efficiency of modern photo converters and electrolyzers is equal to 20 and $80 \%$, respectively, the total efficiency of solar radiant energy transforming into the chemical Hydrogen energy is equal to $16 \%$.

Ulleberg. [15] has developed a mathematical model for an advanced alkaline electrolyzer. A dynamic thermal model has also been developed. Comparisons between predicted and measured data show that the model can be used to predict the cell voltage, Hydrogen production, efficiencies, and operating temperature. The reference system used was the standalone photovoltaic-Hydrogen energy plant in Julich.

A PV-Hydrogen electrolyzes system that was previously investigated by Ramadan et al., 2008 [10] is considered in this work. A mono-crystalline PV module oriented to the south and tilted $30^{\circ}$ with the horizontal was used to power an alkaline hydrogen electrolizer to generate hydrogen. The annual performance is predicted using a computer program called 'TRNSYS 15 simulation program'. A mathematical model was developed to determine and validate the thermal and electrical performance of photovoltaic electrolyzer system using hourly weather data.

\section{Considered System}

An overview of the PV-hydrogen generation system is indicated in Figure (1). This system was successfully installed and testified. The measured data of the system is used to validate the numerical simulation of the system. The system has the following components:

- Electrolyte of $\mathrm{KOH}$ with $30 \%$ salt-concentration.

- The $\mathrm{H}_{2}$-cell of $20 \times 15 \times 13 \mathrm{~cm}$.

- Electrodes of Nicle chrome plates.

- The apart-distance between electrodes is $5-\mathrm{cm}$.

- Mono-crystal PV module that has power $8 \mathrm{w}, \mathrm{V}_{\text {open }}=4 \mathrm{~V}, \mathrm{I}_{\text {sh. }}=6 \mathrm{~A}$. 


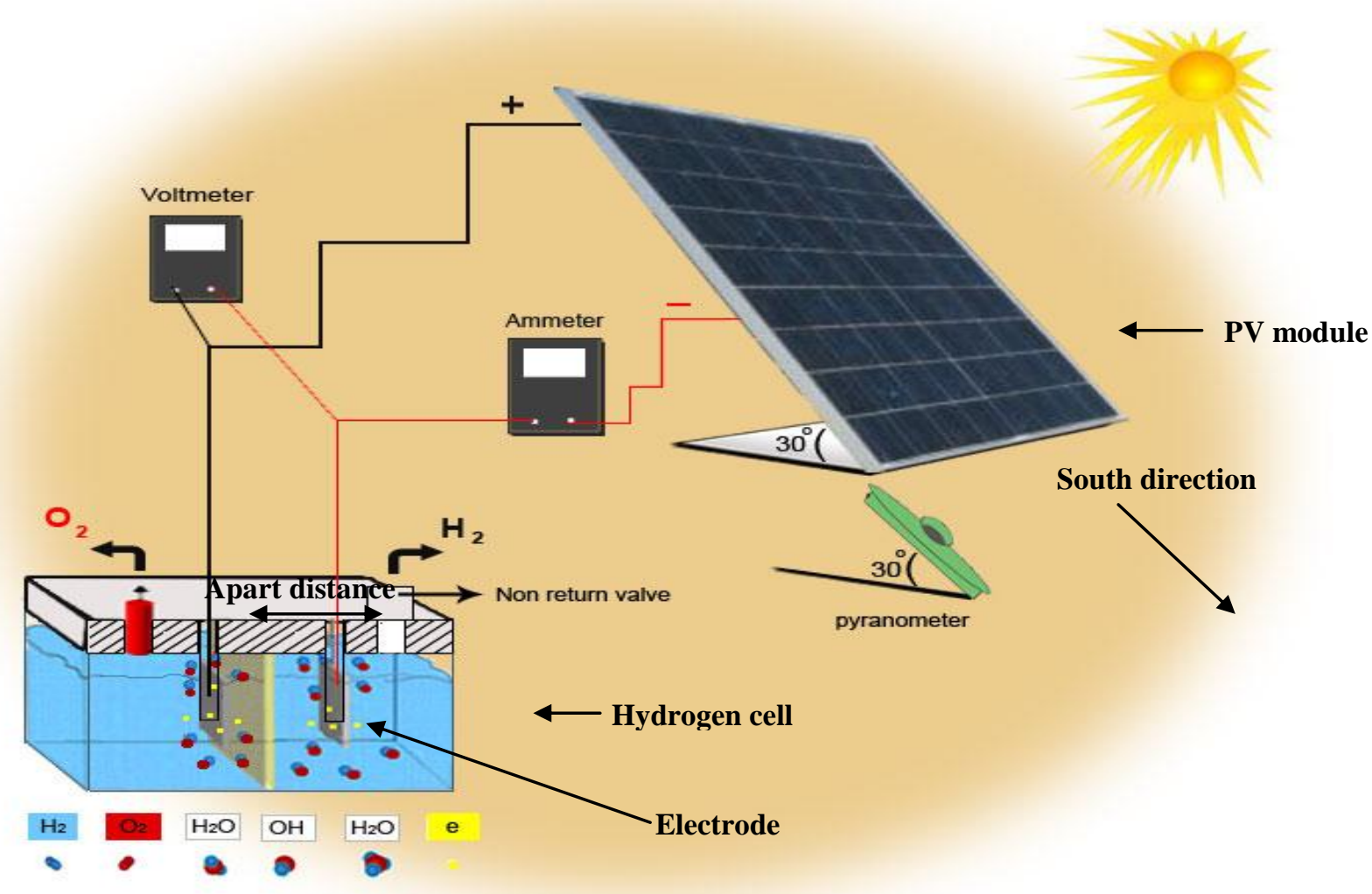

Fig. 1. Schematic diagram of the PV-Hydrogen generation system

\section{Numerical Modeling}

The TRNSYS is a TRANSIENT systems Simulation program with a modular structure. It recognizes a system description language in which the user specifies the components that constitute the system and the manner in which they are connected. The TRNSYS library includes many of the components commonly found in thermal and electrical energy systems, as well as component routines to handle input of weather data or other time-dependent forcing functions and output of simulation results. Trnsys of version 15 is used in this work.

The mathematical model equations have been classified into two parts, one for the PV module to get the output current and voltage needed for Hydrogen production and the other for the Hydrogen flow rate produced from a Hydrogen cell.

\subsection{Mathematical Description of PV Module}

To analyze the performance of PV modules as a power source for hydrogen production, their main parameters such as short circuit current, open circuit voltage and maximum output power should be determined. For simplicity the analysis is based on the following assumptions:

1- The shunt resistance of PV modules is infinite, which is defined as the total leakage paths exist in the cell P-N junction these effect of leakage paths are combined to be called the shunt resistance. So, the current in the shunt resistance can be neglected [11].

2- The short circuit current, $I_{s c}$ of PV modules is equal to their light generated current. $I_{s c}$ current is the current passing from the P-side terminal to $\mathrm{N}$-side terminal when the two terminals of the PV module are connected through a short circuit [1].

3- The series resistance of PV module is independent of incident solar radiation and modules surface temperature. 
As a result of the above assumptions, the output current $(I)$ of PV module connected can be calculated as follows [1]:

$$
I=I_{l}-I_{o}\left[\exp \left(\frac{\left(V+I R_{s}\right)}{V_{t}}-1\right)\right]
$$

$(\mathrm{Vt})$ is the thermal voltage and will be explained latter. The light generated current $\left(\mathrm{I}_{\mathrm{l}}\right)$ of PV module can be calculated according to the following equation [1]:

$$
I_{l}=N_{p}\left(\frac{G}{G_{r}}\right)\left[I_{l r}+\mu_{s c}\left(T_{s}-T_{s r}\right)\right]
$$

where $R_{S}$ is the sum of all resistances of PV cells that can be classified as the following [12]:

- Resistance with the back contact of the P-type silicon.

- The P-type base material resistance.

- Resistance due to the sheet material of the N-type layer.

- Contact resistance between the grid contact and the N-type layer.

- Resistance along the metallic finger and the resistance along the grid collector.

G: Total radiation incident on PV array $\left(\mathrm{W} / \mathrm{m}^{2}\right)$

$\mathrm{G}_{\mathrm{r}}$ : incident radiation at reference conditions (i.e. temperature is $25^{\circ} \mathrm{C}$ and solar radiation is $1000 \mathrm{~W} / \mathrm{m}^{2}$ ).

$\mu_{\mathrm{sc}}: \quad$ Temperature coefficient of short-circuit current $[\mathrm{A} / \mathrm{K}]$.

I $l r: \quad$ Photocurrent at reference conditions (A).

$\mathrm{T}_{\mathrm{S}}$ : $\quad$ Surface temperature of PV module $\left({ }^{\circ} \mathrm{C}\right)$.

$\mathrm{T}_{\mathrm{sr}}$ : $\quad$ Surface temperature of PV module $\left({ }^{\circ} \mathrm{C}\right)$ at reference conditions.

For mono-crystalline silicon PV modules, the surface temperature $\left(\mathrm{T}_{\mathrm{s}}\right)$ can be calculated as function of the meteorological conditions by the following empirical correlation [11]:

$$
T_{s}=\left(27.433 G+1.1225\left(T_{a}-273.15\right)-2.555 W\right)+273.15
$$

The reverse saturation current $\left(\mathrm{I}_{\mathrm{o}}\right)$ of PV module can be calculated as follows [12]:

$$
I_{o}=C N_{p} T_{s}^{3}\left\{\exp \frac{-N_{c} N_{s} V_{g}}{V_{t}}\right\}
$$

Io is the current of minority carriers created by thermal excitation and accelerated within the built in field of the P-N junction.

The thermal voltage $\left(\mathrm{V}_{\mathrm{t}}\right)$ of PV module can be calculated as follows [13]:

$$
V_{t}=\frac{N_{c} N_{s} K T_{s}}{q}
$$

Based on the third assumption, the series resistance $\mathrm{R}_{\mathrm{S}}(\Omega)$ of PV module can be calculated as follows [13]:

$$
R_{s}=\left(\frac{N_{s}}{N_{p}}\right) \frac{\left[V_{t r}-\ln \left(I-\frac{I_{m p r}}{I_{l r}}\right)-V_{m p r}+V_{o c r}\right]}{I_{m p r}}
$$

where

$\mathrm{N}_{\mathrm{p}}$ : Number of modules in parallel in array.

$\mathrm{N}_{\mathrm{S}}$ : Number of modules in series in array. 
$\mathrm{N}_{\mathrm{c}}$ : Number of individual cells in module.

$\mathrm{V}_{\mathrm{tr}}$ : Thermal voltage at reference conditions.

$\mathrm{V}_{\text {ocr }}$ : Open voltage at reference conditions.

The open circuit voltage $\left(\mathrm{V}_{\mathrm{oc}}\right)$ of PV modules can be calculated as follows $[12,13]$ :

$$
V_{o c}=V_{t}\left(\ln \frac{I}{I_{o}}+1\right)
$$

The voltage at maximum power point $\left(\mathrm{V}_{\mathrm{mp}}\right)$ of $\mathrm{PV}$ modules can be estimated by trail and error from the following equation $[1,13]$ :

$$
V_{m p}=V_{o c}-V_{t}\left(\ln \frac{V_{m p}}{V_{t}}+1\right)
$$

The current $\left(\mathrm{I}_{\mathrm{mp}}\right)$ and power $\left(\mathrm{P}_{\mathrm{mp}}\right)$ at maximum power point of PV modules can be computed from the following equations [1]:

$$
\begin{aligned}
& I_{m p}=I_{l}\left(1-\frac{V_{t}}{V_{m p}}\right) \\
& P_{m p}=V_{m p} I_{m p}
\end{aligned}
$$

According to the previous equations, they need some constants or input data of the module to produce the simulated parameters required for the hydrogen production simulation. These data are given by the manual of PV module used in the experimental measuring.

\subsection{Mathematical Description of Hydrogen Generation Cell.}

A mathematical model is developed to describe the process of Hydrogen generation in Hydrogen cell. These equations are a function in input voltage and current, electrode area electrolysis temperature, hydrogen enthalpy, entropy and resistance of electrolysis. The equations are listed as follows:

\section{Change in Gibbs energy}

The Gibbs free energy is $(\Delta \mathrm{G})$ the maximum amount of non-expansion work which can be extracted from a closed system or this maximum can be attained only in a completely reversible process [15].

$$
\Delta \mathrm{G}=\Delta \mathrm{H}-\left(\Delta \mathrm{S} \times \mathrm{T}_{\text {elct. }}\right)
$$

\section{Thermo neutral cell voltage $\left(V_{\text {tn }}\right)$}

Thermo neutral cell voltage is the minimum potential difference between the cathodes, where hydrogen is released (reduction), and the anode, where oxygen is released (oxidation), should be $1.482 \mathrm{~V}$ [15].

$$
\mathrm{V}_{\mathrm{tn}}=\frac{\Delta H}{z F}
$$

\section{Reversible cell voltage}

The emf (V) for a reversible electrochemical process, or the reversible cell voltage,

$$
\mathrm{V}_{\text {rev. }}=\frac{\Delta G}{z F}
$$

\section{Electrolyze cell voltage}

The input voltage to the electrolysis cell

$$
\mathrm{V}_{\text {elct. }}=\mathrm{V}_{\text {rev }}+\left(\left(\left(\mathrm{r}_{1}+\left(\mathrm{r}_{2} * \mathrm{~T}_{\text {elct }}\right)\right) / \mathrm{A}\right) * \mathrm{I}_{\mathrm{ELY}}\right)+\mathrm{s} * \log \left(\left(\mathrm{t}_{1}+\left(\mathrm{t}_{2} / \mathrm{T}_{\text {elct }}\right)+\left(\mathrm{t}_{3} / \mathrm{T}_{\text {elct }}{ }^{2}\right)\right) *\left(\mathrm{I}_{\mathrm{ELY}} / \mathrm{A}\right)+1\right)
$$




\section{Faraday efficiency}

$$
\eta_{F}=\frac{\left(\frac{I_{e l y}}{A}\right)^{2}}{f_{1}+\left(\frac{I_{e l y}}{A}\right)^{2}} f_{2}
$$

The Faraday Efficiency of electrolysis is defined as the ratio of "the actual quantity of material released", to "the theoretical quantity of material which should have been released, based on Faraday's laws of electrolysis".

\section{Hydrogen flow rate (1/h)}

$$
Q=\eta_{F} \frac{I_{\text {ely }}}{z F} \times 3600 \times 0.224136 \times 1000
$$

\section{The total efficiency}

$$
\eta_{\text {total }}=\frac{Q E}{A_{m} G}
$$

Required input data to equations are called simulated parameters as independent values which must be defined in the mathematical model, the parameter's constants needed for the process of simulation are considered from the practical data.

\section{Result and Discussion}

According to the whole mathematical formulas mentioned, it is very important to make a validation to the previous equations with the experimental data which are established. After that the annual performance of the $\mathrm{PV}-\mathrm{H}_{2}$ system is presented. The monthly average incident solar energy on the PV module as well as the monthly average maximum output energy of PV module is calculated. The annual hydrogen flow rate outlet from the electrolyzer as well as the hydrogen quantity is estimated. The annual overall photovoltaic hydrogen electrolyzer system efficiency is presented.

\subsection{Validation of Simulation Data with Experimental One.}

A comparison between predicated and measured data is needed to make a validation for the simulation and to know if this predicated data can visualize accurately the system performance. All that is developed to establish a validated PV-Hydrogen program which it can be optimized and improved. The model or simulated program can be used to predict, cell voltage, operating current, hydrogen production and overall efficiency.

For a right simulation it is needed to know some parameters and constants that are:

1. Hourly measured radiation and ambient temperature for a year.

2. PV characteristics and orientation.

3. Constants of hydrogen cell reaction equations.

4. Hydrogen cell size and geometry.

The following figures illustrate the simulated and measured data and how they differ or match with each other. They are computed under the same conditions of weather and specifications. 


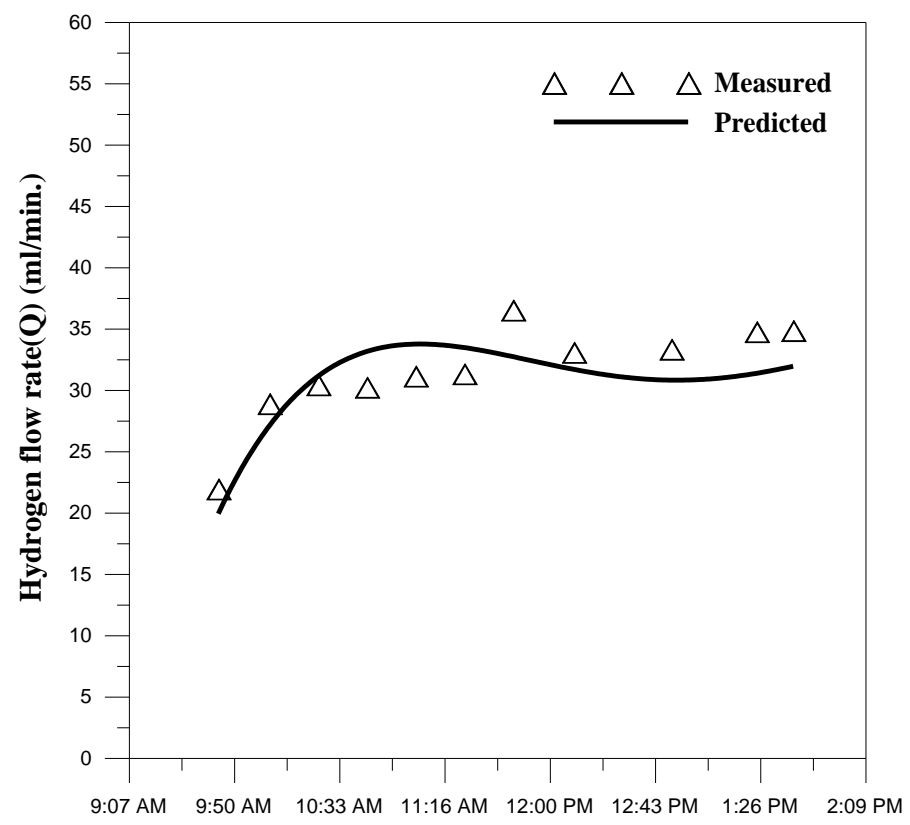

Local Time

Fig. 2. Simulated and experimental Hydrogen flow rate with local time at August. 13, 2007

As shown in figure 2, the simulated hydrogen flow rate approximately agrees with that produced experimentally, where in midday the flow rate is getting its maximum value. As shown in the figure there is a slight difference between the measured and predicted $\mathrm{H}_{2}$ flow rate during the day hours, it is about $4 \%$. The predicted hydrogen flow rate is greater than the measured value due to the larger simulated current than real current. This increase of simulated current is coming from that Trnsys program considers that there is no loss during system connections. In addition, the PV panel performance is theoretically modeled and the normal actual losses are ignored.

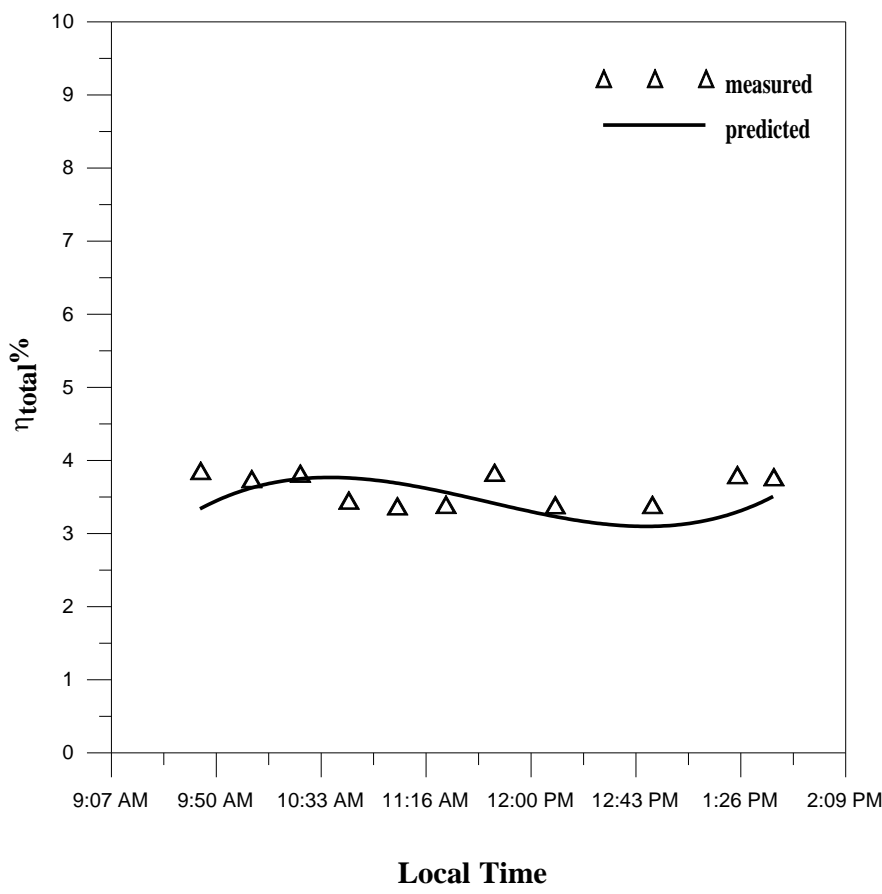

Fig. 3. Simulated and experimental Overall system efficiency at August. 13, 2007 
The overall efficiency of the system is ranged from 2.8 to $4.2 \%$ in both simulated and experimentally data as seen in figure 3 . The overall efficiency difference is small and can be accepted and it ranges from 1 to $4.5 \%$.

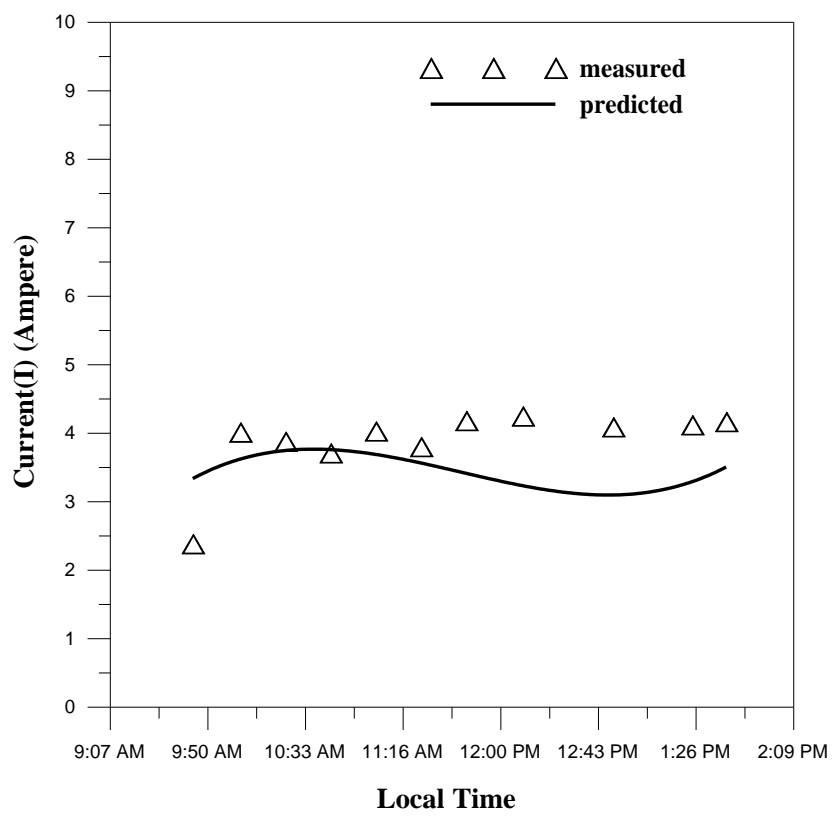

Fig. 4. Simulated and experimental operating current at August. 13, 2007

As mentioned before the simulated current is higher than actual one, it reasonably ranges between 1 to 2 Ampere as in figure 4 . That lets the predicted hydrogen flow rate is higher than measured one as indicated in figure 1.

From the previous figures it is clear that the approach of simulated data output and experiments, with percent of difference approximately ranged from 1 to $4 \%$. That can be accepted for the simulated systems in this manner.

\subsection{Annual Performance of the Solar System}

According to previous facts obtained, it can be said that, the simulation program is validated and it can be used for the predication of the considered system performance annually. That can eliminate the installation cost of such system. It needs solar radiation and ambient temperature specified for a location of PV module.

Figure 5 indicates the solar radiation along a year which is measured hourly for Cairo $30{ }^{\circ} \mathrm{N}$. The maximum solar radiation can be seen at the winter season where the maximum value can be reached to $1150 \mathrm{~W} / \mathrm{m}^{2}$. In summer season the solar radiation gets down than winter and that because of higher value of humidity ratio and pollution in air which decreases the amount of solar radiation reaching the earth. The lower apart distance from the sun in winter is other factor for that.

Solar radiation also in some time gets to 0 or the minimum which is viewed as white line in the figure, this is because the measured data at that time may be performed when the clouds in the sky are heavy and prevents the sun rays to reaching the surface of earth in this area of measurements otherwise it is at night hours. 


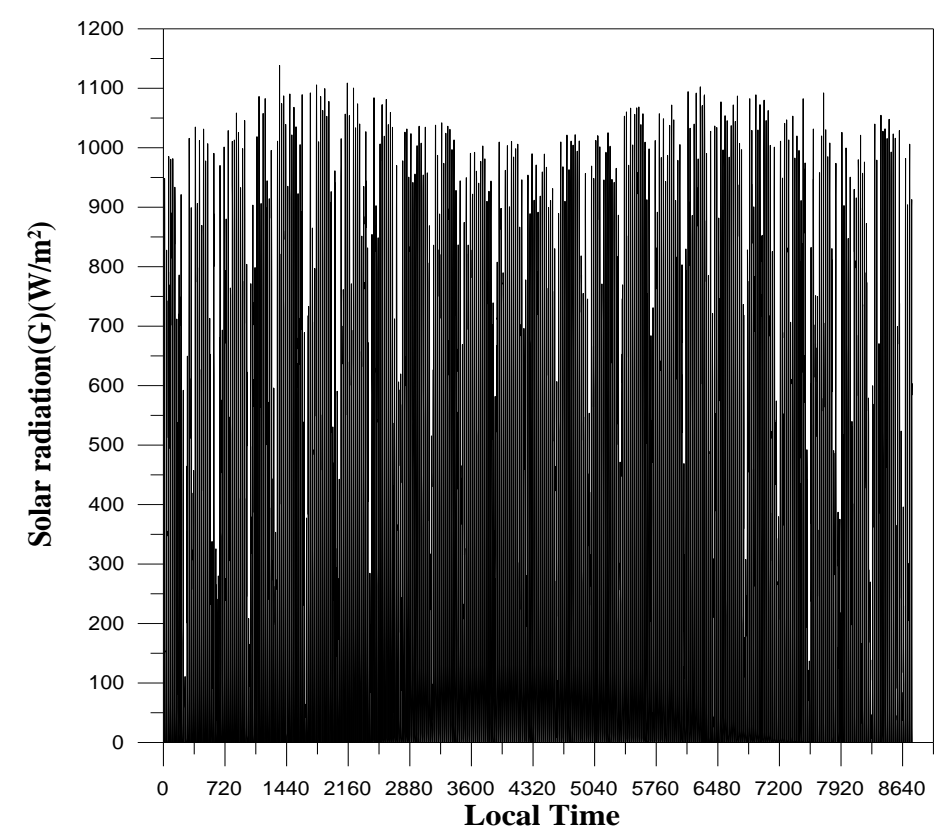

Fig. 5. Annual variation of measured solar radiation

Figure 6 describes the annual Hydrogen production according to the solar radiation measured. As seen in that figure the trend of the curve is the same as the solar radiation in figure 5. It can be said that the amount of solar radiation is affecting Hydrogen production as the main parameter or the only energy source. The maximum value of hydrogen flow rate is reached where the solar radiation is maximized in the winter season and can be reached to $43 \mathrm{ml} / \mathrm{min}$. Accordingly the hydrogen is being zero due to the zero solar radiation. Therefore, the strong evidence is clear that solar radiation has the major affected parameter in the Hydrogen production in PV electrolysis system. The annual hydrogen production by the considered PV module is about 41407931.97 liters

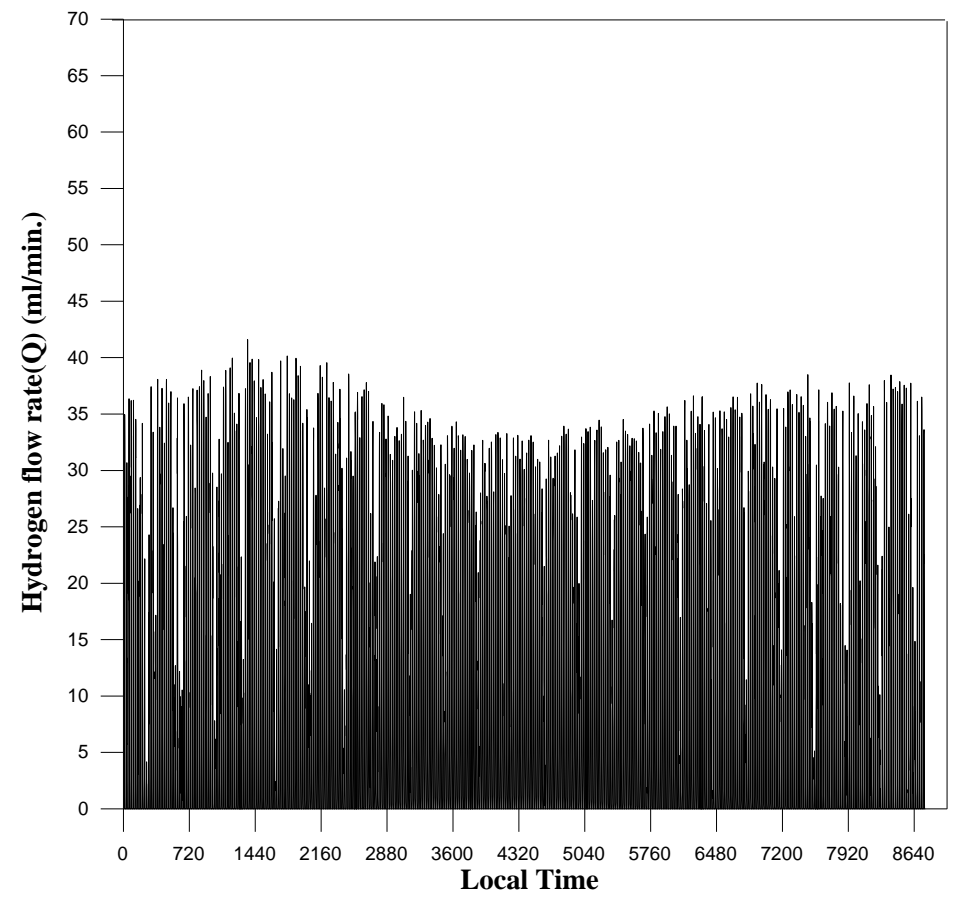

Fig. 6. Annual accumulated Hydrogen flow rate 


\section{Conclusion}

A numerical simulation was developed for an experimentally optimized PV-hydrogen system. The simulation results are successfully verified with the corresponding measured data under the same conditions of weather and system geometry. It is found that the simulated Hydrogen flow rate approximately agrees with that produced experimentally and the difference between the measured and predicted $\mathrm{H}_{2}$ flow rate during the day hours is about $4 \%$. The overall efficiency difference is also small and can be accepted, it ranges from 1 to $4.5 \%$. The annual production of hydrogen using such system is about 41407931.97 liters where the maximum Hydrogen generation is $43 \mathrm{ml} / \mathrm{min}$. The overall efficiency of the system along the year is ranged between 2.45 to $2.75 \%$.

\section{6- References}

[1] F .Lasnier and TG.Ang," Photovoltaic engineering handbook". New York: Adam Hilger; 1990.

[2] MA.Green, "Solar cells operating principles, technology", and system applications. Englewood Cliffs: Prentice-Hall, Inc.; 1982.

[3] D. T. Reindl, et al, "Evaluation of Hourly Tilted Surface Radiation Models", Solar Energy, Vol. 45, No. 1, 1990, pp. 9-17.

[4] H.Blank and A.Suzuki, "Solar Hydrogen Demonstration Plant in Neunburgvorm Wald", in T.N.Veziroglu, C. Derive, and J. Pottier, eds., Hydrogen Energy Progress IX, Vol. 2, pp. 677-686, M.C.I., Paris, 1992.

[5] W. Grasse, F. Oster, and H. Aba-Cud. Hysolar: "The German- Saudi Arabian Programm on Solar Hydrogen- 5 Years of Experience", Int. J. Hydrogen Energy, Vol. 17, No. 1. pp. 1-8, 1992

[6] P. Lehman and C.E. Chamberlian. "Design of a Photovoltaic - Hydrogen -Fuel Cell Energy System", Int. J. Hydrogen Energy, Vol.16, No.5, pp. 349-352, 1991.

[7] P.D. Lund, "Optimization Of Stand Alone Photovoltaic System with Hydrogen Storage for Total Energy Self-Sufficiency", Int. J. Hydrogen Energy, Vol.16, No. 11, pp. 735740, 1991.

[8] A.G. Garcia and F. Rosa. "Solar Hydrogen Production: A Spanish Experience", in T.N. Veziroglu, C. Derive, and J. Potter, eds., Hydrogen Energy Progress IX, Vol. 2, M.C.I., Paris, pp. 723-732, 1992.

[9] Kerimov et al, "Modeling to get Hydrogen and Oxygen by Solar water electrolysis", Int. J. Hydrogen Energy, No. 26, pp. 195-201, 2001.

[10] Ramadan and et al "Optimization of PV-Hydrogen Electrolyzes System"Solar Energy Dept., National Research Centre, Tahrir St., Dokki, Cairo.

[11] GE. Ahmad, "Impacts of local meteorological conditions on the operation and performance of PV panels". M.Sc Thesis. Ain Shams University, Faculty of Engineering, Electrical Power and Machines Engineering Dept., Cairo, Egypt, 1992.

[12] MA.Green, "Solar cells operating principles, technology", and system applications. Englewood Cliffs: Prentice-Hall, Inc.; 1982.

[13] JA .Duffie, "Solar engineering of thermal processes". New York: John Wiley and Sons, Inc.; 1991.

[14] Trnsys manual. Trnsys version 15.

[15] Oystein Ulleberg, "Modeling of advanced alkaline electrolyzers: a system simulation approach", International Journal of Hydrogen Energy 28 (2003) 21-33. 